07

\title{
Механизмы тока в слоях электроосажденных субмикронных полупроводниковых частиц
}

\author{
(С) Н.Д. Жуков ${ }^{1}$, Д.С. Мосияш ${ }^{1}$, И.В. Синёв ${ }^{2}$, А.А. Хазанов ${ }^{1}$, \\ А.В. Смирнов ${ }^{2}$, И.В. Лапшин ${ }^{3}$ \\ ${ }^{1}$ OОО „Рефр-Свег“, Саратов \\ ${ }^{2}$ Саратовский государственный университет им. Н.Г. Чернышевского \\ ${ }^{3}$ АО „ГИРЕДМЕТ“, Москва \\ E-mail: ndzhukov@rambler.ru
}

Поступило в Редакцию 27 декабря 2016 г.

Исследованы вольт-амперные характеристики (BАХ) проводимости в мультизеренных слоях субмикронных частиц кремния, арсенида галлия, арсенида и антимонида индия. Наночастицы получены помолом монокристаллов на шаровой мельнице и после седиментации нанесены на подложки электроосаждением. Детальный анализ ВАХ позволил установить, что их поведение определяется механизмом межзеренной туннельной эмиссии из приповерхностных электронных состояний субмикронных частиц. Определены параметры эмиссионного процесса. Использование мультизеренных полупроводниковых структур возможно в газовых и оптических сенсорах, приемниках ИК-излучений.

DOI: 10.21883/PJTF.2017.24.45344.16641

В исследованиях и разработках все более широкое применение находят субмикронные частицы полупроводников [1]. Например, тонкие пленки из наночастиц кремния $(n c-\mathrm{Si})$, мультикристаллические структуры из зерен кремния, структурированный из разных форм наночастиц оксид цинка рассматриваются как перспективные элементы солнечных батарей [2-4].

Одним из методов создания структур из наночастиц разных материалов является технология электрофоретического осаждения [5,6], ранее хорошо развитая и широко используемая в производстве электроннолучевых трубок и катодолюминесцентных дисплеев [7]. Этим методом формируется слоистая структура из частиц-кристаллитов, которую для случаев полупроводников можно назвать мультикристаллической [3] 
или мультизеренной по аналогии с металлами [8]. Электрофизические и оптические свойства такой структуры зависят от размеров и формы зерен-кристаллитов, степени их соприкосновения, среды заполнения межзеренного пространства.

В настоящей работе проведено исследование механизмов тока в мультизеренных слоях наиболее перспективных для приложений полупроводников: кремния, арсенида галлия (GaAs), арсенида индия (InAs) и антимонида индия (InSb). Особый интерес при этом представляют полупроводники группы $\mathrm{A}_{3} \mathrm{~B}_{5}$, для которых могут наблюдаться квантоворазмерные эффекты в частицах относительно больших размеров [9-11].

Используемые в работе субмикронные порошки изготавливались из монокристаллических полупроводников электронной проводимости с концентрацией электронов (по данным паспортасертификата) $N \sim 5 \cdot 10^{17}-5 \cdot 10^{18} \mathrm{~cm}^{-3}$ и удельным сопротивлением $\rho \sim 0.01-1 \Omega \cdot \mathrm{cm}$ путем их измельчения в шаровой мельнице Pulverisette-7 (Fritch, Германия). Измельчение осуществлялось в три этапа: шарами из карбида вольфрама диаметром 10.5 и $1 \mathrm{~mm}$ (в течение $10 \mathrm{~h}$ на каждом этапе). Частота вращения размольного стакана составляла $450 \mathrm{rpm}$. Частицы имели широкий разброс по размерам (от десятков нанометров до десяти микрометров). Форма частиц была полигональной. С учетом оценок предела прочности субмикронных частиц с использованием модели пластической деформации и соотношения Холла-Петча [12] полагалось, что полученные частицы с размерами на минимальном пределе не имели нарушенной по сравнению с исходными монокристаллами структуры. Методом седиментации проводился отбор субмикронных частиц с размерами на минимальном пределе.

Покрытия из нанопорошков формировались методом катафореза в тонкой $(\sim 1 \mathrm{~mm})$ плоской ячейке. Состав суспензии аналогичен применяемому для нанесения порошков люминофора в производстве катодолюминесцентных дисплеев [7]: на $50 \mathrm{ml}$ изопропилового спирта 2 g нанопорошка, $1 \mathrm{ml} 0.1 \mathrm{M}$ водного раствора зарядчика $\left[\mathrm{Al}\left(\mathrm{No}_{3}\right)_{3}+\mathrm{La}\left(\mathrm{NO}_{3}\right)_{3}\right]$ и $0.3 \mathrm{ml}$ диспергента (глицерин). Суспензия обрабатывалась ультразвуком при помощи погружного зонда в течение $3 \mathrm{~h}$ при непрерывном перемешивании. Режим нанесения - постоянное напряжение (15 V), без подогрева. Время осаждения варьировалось в пределах до одной минуты и определяло толщину покрытия. После окончания процесса осаждения образец промывался в ацетоне и сушился на воздухе при температуре $120^{\circ} \mathrm{C}$.

Письма в ЖТФ, 2017, том 43, вып. 24 


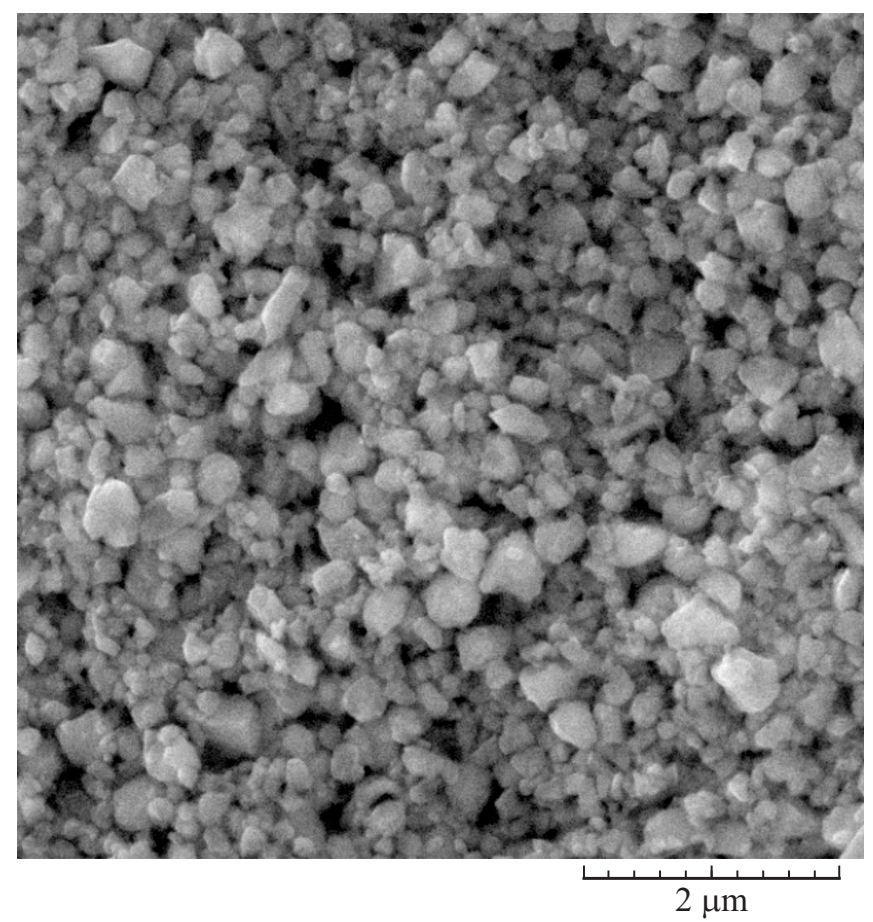

Рис. 1. Типичное СЭМ-изображение поверхности покрытий из субмикронных частиц.

Толщина слоя покрытия $l$ составляла $\sim 2 \mu \mathrm{m}$. На рис. 1 приведено типичное СЭМ-изображение (СЭМ - сканирующая электронная микроскопия) поверхности полученных мультизеренных слоев. Были построены гистограммы распределения размеров частиц в слое. Средние размеры частиц в зависимости от типа полупроводника для InSb coставляли $0.37 \mu \mathrm{m}$, для остальных $-0.22-0.23 \mu \mathrm{m}$, средние отклонения находились в пределах до $0.3 \mu \mathrm{m}$, значения удельной поверхности $15-25 \mu \mathrm{m}^{-1}$. Объем межзеренного пространства в слое, определяемый по весовым параметрам, порядка 15\%. Рассчитанное по этим данным значение среднего размера межзеренных зазоров в слое составляло порядка $10 \mathrm{~nm}$.

Письма в ЖТФ, 2017, том 43, вып. 24 


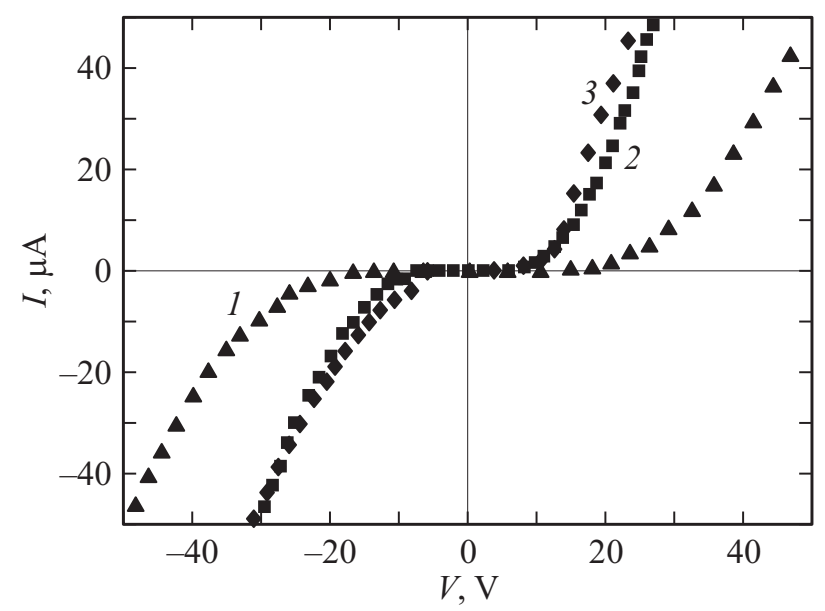

Рис. 2. Типичные BAX образцов: $1-\mathrm{InSb}, 2-\mathrm{GaAs}, 3-\mathrm{InAs}$.

В качестве электродов к нанесенному слою использовались пленки ITO. Слоистое покрытие из ITO и зерен полупроводника наносилось на подложки из стекла толщиной $\sim 0.5 \mathrm{~mm}$ в виде полосок шириной $\sim 3 \mathrm{~mm}$, длиной $\sim 10 \mathrm{~mm}$. Для формирования тестовых образцов две такие пластинки соединялись зажимом сторонами с нанесенным материалом. Таким образом, тестовые образцы имели мультизеренный слой толщиной $\sim 4 \mu \mathrm{m}$ и площадью $\sim 10 \mathrm{~mm}^{2}$. Было изготовлено более 20 образцов.

Для измерений вольт-амперных характеристик (ВАХ) использовался нестандартный генератор однополярного низкочастотного импульсного „пилообразного“ напряжения до $300 \mathrm{~V}$, длительность импульсов $500 \mu \mathrm{s}$, скважность 128. Параметры элементов схемы и режимов подбирались с учетом отсутствия влияния на BAX частоты и длительности импульсов. Переходные процессы контролировались по осциллограммам. Анализ проводился с использованием обработки экспериментальных BAX в таблицах Microsoft Excel. Аппроксимация кривых аналитическими формулами выполнялась при максимальных значениях величин коэффициентов достоверности, но не менее 0.99 .

На рис. 2 показаны ВАХ образцов в линейных координатах. Во всех случаях ВАХ были симметричными относительно центра координат.

Письма в ЖТФ, 2017, том 43, вып. 24 


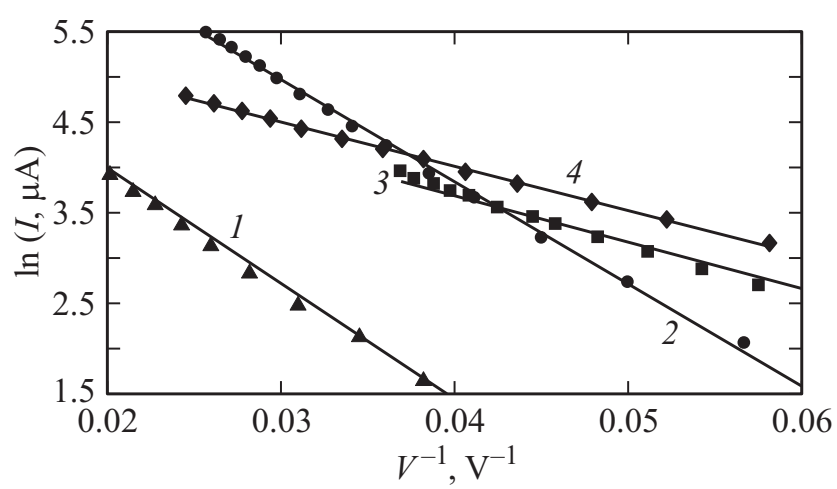

Рис. 3. Типичные ВАХ образцов в полулогарифмических координатах: $1-\mathrm{InSb}, 2-\mathrm{InAs}, 3-\mathrm{GaAs}, 4-\mathrm{Si}$.

На рис. 3 представлены ВАХ образцов в полулогарифмических координатах.

При анализе ВАХ тщательно исследован вопрос об омических контактах. Для этого изготавливались образцы с минимально возможной толщиной покрытия (менее $0.5 \mu \mathrm{m})$, близкой к толщине однозеренного слоя. Измеренные при этом ВАХ были линейными, а произведение сопротивления на площадь $R S$ составляло величину менее $1 \Omega \cdot \mathrm{cm}^{2}$. Известные из литературы экспериментальные данные для омических контактов к полупроводникам группы $\mathrm{A}_{3} \mathrm{~B}_{5}$ имеют примерно тот же порядок [13]. Величины $R S$ мультизеренных структур (рис. 2) достигают сотен $k \Omega \cdot \mathrm{cm}^{2}$, что свидетельствует о том, что определяющие ВАХ процессы протекают в объеме слоя, а не на границах с электродами.

Оценки значений $R S=\rho l$ для пленок в предположении, что они сплошные, дают ничтожно малые величины $\left(<10^{-4} \Omega \cdot \mathrm{cm}^{2}\right)$ по сравнению с измеренными (до $10^{6} \Omega \cdot \mathrm{cm}^{2}$, рис. 2). Это позволяет считать, что определяющие BAX процессы тока протекают на границах зерен и в зазорах между ними. При этом напряжение полностью падает на межзеренных зазорах, создавая поле достаточных для эмиссии величин.

Многочисленные публикации по мультизеренным материалам относятся к структурам плотной упаковки с практически нулевыми зазорами между зернами. Для них используются модели рассеяния электронов на границах зерен для металлов и контактных явлений для полупроводников. В обзоре [13] приведены результаты расчетов $R S$ контактов 
металл-полупроводник в разных моделях, одна из которых - вариант полевой эмиссии - дает величины, подобные полученным в нашей работе (до $10^{6} \Omega \cdot \mathrm{cm}^{2}$, рис. 2). Явной спецификой нашего случая являются относительно большие зазоры между зернами, оцененные выше в среднем как $10 \mathrm{~nm}$. При таких размерах электроны испытывают эмиссию из зерна в зазор и инжекцию из зазора в зерно. Эти процессы исследованы нами на отдельных зернах с использованием метода сканирующей туннельной микроскопии [9-11,14,15].

Аппроксимация проводилась нами по всем вариантам функциональной зависимости, описывающим процессы переноса электронов, и соответственно ВАХ полупроводниковых гетероструктур: $\ln I \sim \ln V$, $\ln I \sim V, \ln I \sim 1 / V ; \ln \left(I / V^{2}\right) \sim 1 / V$. Из всех вариантов лучшие результаты аппроксимации давала зависимость $\ln I \sim 1 / V$ (рис. 3 ).

ВАХ вида $\ln I \sim(A-B / V)$ можно объяснить механизмом туннельной эмиссии электронов с приповерхностных уровней полупроводника $[13,16,17]$. Сравнение с расчетной формулой для эмиссии электронов в полупроводнике с приповерхностных уровней на вакуумный [16] позволяет получить выражение для В:

$$
B \sim 8 \pi \psi^{3 / 2}(2 m)^{1 / 2}(q h E)^{-1} F(E, \psi),
$$

где $E$ - напряженность электрического поля в эмитирующем слое, $\psi-$ величины барьера для электронов при эмиссии, $m$ - эффективная масса электрона, $h$ - постоянная Планка, $q$ - заряд электрона, $F(E, \psi)-$ поправочная табулированная функция Нордгейма, определяемая по величине (от 0 до 1) уменьшением работы выхода $\Delta \psi$ за счет сил изображения (эффект Шоттки) [16]. При этом полупроводниковая специфика эмиссии функционально выражена также и в параметре $A$, который слабо зависит от $E$ [16].

Величина тока поперек планарного слоя образца складывается из величин множества параллельных токовых линий, а ток в каждой из этих линий определяется эмиссией электронов в некоем числе зазоров между парами последовательного ряда частиц. Размеры зазоров $Z_{j}$ различны для разных пар частиц каждого ряда.

Пусть в каждой отдельной $i$-й линии тока среднее значение величин зазоров есть $Z_{i}^{*}$, а их число $-N_{i}$. Полагая, что значения $B E$ (см. (1)), являющиеся параметром полупроводника, одинаковы для всех зерен, можно записать ВАХ для каждой из зеренных пар: $I_{i} / I_{0 i} \sim \exp \left(-B Z_{j} / V_{j}\right)$, где $V_{j}$ - падение напряжения на $j$-й зеренной

Письма в ЖТФ, 2017, том 43, вып. 24 
паре. Находя из этого выражения $V_{j}$ и суммируя, получаем для ВАХ $i$-й токовой линии $I_{i} I_{0} \exp \left(-B Z_{1}^{*} N_{i} / V\right)$. Полагая, что величины $Z_{i}^{*} N_{i}=Z^{*} N$ одинаковы для всех линий тока (благодаря большому количеству зеренных пар в структуре) и суммируя по $i$, можно записать выражение для ВАХ всей структуры

$$
I / I_{0} \sim \exp \left(-B_{0} Z^{*} N / V\right), B_{0} \sim 3.5\left(m / m_{0}\right)^{1 / 2} \psi^{3 / 2} F,
$$

где $Z^{*} N$ имеет размерность $\mathrm{nm}$, а $\psi-\mathrm{eV}$.

В случаях величин поля менее $10^{7} \mathrm{~V} / \mathrm{cm}$ влиянием эффекта Шоттки можно пренебречь, поскольку тогда изменение $\psi$ несущественно (не более $10 \%$ ). В этом случае в формуле (2) можно принять $F \sim 1$ [16].

Для нахождения величин $B_{0}$, являющихся параметром полупроводников, были проведены измерения BAX на туннельном микроскопе по методике, описанной в работе [14]. Таким способом найдены значения $B_{0}(\mathrm{~V} / \mathrm{nm})$ : для $\mathrm{InSb}-\sim 2.5$, для InAs $-\sim 4.0$, для GaAs $\sim \sim 5.0$. Эти значения практически совпадают с расчетными по литературным данным для параметров $m / m_{0}$ и $\psi$. Для кремния было использовано расчетное значение $B_{0} \sim 12 \mathrm{~V} / \mathrm{nm}$.

По ВАХ, приведенным на рис. 3, и формуле (2) определены значения $B_{0} N Z^{*}(V)$ : для $\mathrm{InSb}-\sim 125$, для InAs $-\sim 110$, для GaAs $80, \mathrm{Si}-\sim 70$. Тогда делением этих величин на значения $B_{0}$ находятся значения величин $N Z^{*}(\mathrm{~nm})$ : для $\mathrm{InSb}-50$, для InAs $-\sim 30$, для $\mathrm{GaAs}-15$, для $\mathrm{Si}-\sim 5$. Делением на эти значения величин падения напряжения (рис. 2) определяется пороговая напряженность поля в зазорах эмиссии $(\mathrm{V} / \mathrm{cm})$ : для $\mathrm{InSb}-4 \cdot 10^{6}$; для $\mathrm{InAs}-6 \cdot 10^{6}$, для $\mathrm{GaAs}-\sim 8 \cdot 10^{6}$, для $\mathrm{Si}-2 \cdot 10^{7}$. Эти значения (кроме случая $\mathrm{Si}$ ) в 5-10 раз меньше, чем для металлов [16], что обусловлено спецификой эмиссии в полупроводниках с малыми величинами эффективной массы электронов $(m / m 0<0.1)$.

Таким образом, в мультизеренной слоистой структуре исследованных полупроводников определяющим для тока является туннельноэмиссионный механизм в межзеренных зазорах. Благодаря этому вольтамперные характеристики подчиняются функциональной зависимости вида $I / I_{0} \sim \exp \left(-B_{0} Z^{*} N / V\right)$, параметр в экспоненте имеет значения порядка $100 \mathrm{~V}$, а среднесуммарные величины зазоров $Z^{*} N-\sim 15-50 \mathrm{~nm}$. При действии этого механизма на ВАХ существенное влияние (через параметр $B_{0} Z^{*}$ ) окажут электромагнитное излучение и состояние среды в межзеренном пространстве. Такие структуры могут быть использованы в газовых и оптических сенсорах, приемниках ИК-излучений.

Письма в ЖТФ, 2017, том 43, вып. 24 
Монокристаллы полупроводников $\mathrm{A}_{3} \mathrm{~B}_{5}$ предоставлены $\mathrm{AO}$ „ГИРЕДМЕТ“.

Исследование выполнено при финансовой поддержке РФФИ в рамках научных проектов № 16-07-00136-а и 16-38-00633-мол_а.

\section{Список литературы}

[1] Третьяков Ю.Д. // Нанотехнологии. Экология. Производство. № 1(8), 98 (2011).

[2] Дорофеев С.Г., Кононов Н.Н., Звероловлев В.М. и др. // ФТП. 2014. Т. 48. B. 3. C. 375-383.

[3] Пещерова С.М., Непомнящих А.М., Павлов Л.А. и др. // ФТП. 2014. Т. 48. B. 4. C. $492-497$.

[4] Бобков А.А., Максимов А.И., Мошников В.А. и др. // ФТП. 2015. Т. 49. В. 10. C. 1402-1406.

[5] Филиппов Н.С., Вандышева Н.В., Паращенко М.А. и др. // ФТП. 2014. Т. 48. B. 7. C. 995-1001.

[6] Клочко Н.П., Хрипунов Г.С., Мягченко Ю.А. и др. // ФТП. 2014. Т. 48. В. 4. C. 549-555.

[7] Dmitrienko A.O., Strel'sov A.V., Gorfinkel B.I. et al. // Proc. of the 27th Int. Display Research Conf. „EuroDisplay-2007“،. M.: Society for Information Display, 2007. P. 113-115.

[8] Овчаренко В.Е., Боянгин Е.Н., Мышляев М.М. и др. // ФТТ. 2015. Т. 57. B. 7. C. 1270-1276.

[9] Глуховской Е.Г., Жуков Н.Д. // Письма в ЖТФ. 2015. Т. 41. В. 14. С. 47-55.

[10] Михайлов А.И., Кабанов В.Ф., Жуков Н.Д. // Письма в ЖТФ. 2015. Т. 41. B. 21. C. 88-94.

[11] Жуков Н.Д., Глуховской Е.Г., Мосияш Д.С. // Письма в ЖТФ. 2015. Т. 41. B. 22. C. 1-7.

[12] Глезер А.М., Столяров В.Л., Томчук А.А. и др. // Письма в ЖТФ. 2016. Т. 42. B. 1. C. $103-110$.

[13] Бланк Т.В., Гольдберг Ю.А. // ФТП. 2007. Т. 41. В. 11. С. 1281-1308.

[14] Жуков Н.Д., Глуховской Е.Г., Мосияш Д.С. // ФТП. 2016. Т. 50. В. 7. С. $911-$ 917.

[15] Жуков Н.Д., Глуховской Е.Г., Хазанов А.А. // ФТП. 2016. Т. 50. В. 6. С. $772-$ 776.

[16] Егоров Н.В., Шешин Е.П. Электронная эмиссия. М.: Интеллект. 2011. 703 с.

[17] Гольдман Е.И., Гуляев Ю.В., Ждан А.Г., Чучева Г.В. // ФТП. 2010. Т. 44. B. 8. C. $1050-1052$.

Письма в ЖТФ, 2017, том 43, вып. 24 